\title{
Editorial: Watering holes
}

\author{
Christopher H Knight*
}

University of Copenhagen Faculty of Medical Sciences, DK1870 Frb C, Denmark

Water, water everywhere, but did you ever stop to think; Water, water everywhere, so what did the albatross drink? These lines are adapted (rather ineptly) from Samuel Taylor Coleridge's famous poem, The Rime of the Ancient Mariner. Coleridge did not answer my question, and in all probability never even thought about it. The answer is surprisingly simple; seabirds are able to survive quite happily on seawater because they have the ability to secrete large amounts of sodium chloride through their salt glands. This is not as esoteric for a lactation Journal as it might sound: the physiology underpinning ion and fluid secretion by the mammary gland was first described by Jim Linzell and Malcolm Peaker (Linzell \& Peaker, 1971), who also worked on these related processes in avian salt glands. More recently the channels responsible for transporting water across the otherwise impermeable lipid bilayer membrane of the mammary secretory cell have been identified as aquaporins (Mobasheri \& Barrett-Jolley, 2014). From a physiological point of view, water balance and lactation are intricately entwined. Prolactin, originally named for its lactation regulating properties in the rabbit, was subsequently shown to be an ancient hormone involved in water balance in many species, and one of the theories for the evolution of lactation (there are others) is as a water source to prevent the eggs of synapsids from drying out (Oftedal, 2002). The complexities of balancing water balance and lactation become obvious as soon as one realises that a concentrated milk favours the mother but compromises the neonate, and vice versa for dilute milks. Numerous adaptations have emerged. Some lactating desert rodents will drink the dilute urine of their offspring as they suckle, hence recycling water, whilst lactating ruminants have the advantage of a large reticulorumen that allows them to drink copiously and rapidly when water is available, without suffering water intoxication (Olsson, 2005). Simultaneously with hugely increasing demands for food, our planet also faces major challenges of water scarcity (Mekonnen \& Hoeskstra, 2016). Listening to a politically-inspired debate on water scarcity at a recent EAAP Conference I was struck by the fact that production animals were being almost entirely ignored, since 'they account for less than $2 \%$ of water usage'. Whilst this may be true (more or less: there is intense debate and little

*For correspondence; e-mail: chkn@sund.ku.dk agreement on how to best measure global water supply and usage), it ignores the obvious fact that animals would not survive without that $2 \%$. There are holes in our water knowledge, so a future issue of the Journal of Dairy Research will reexamine this crucial issue. More imminently we shall consider a second and equally important aspect of dairy-related water usage, that which occurs in our processing industries. DairyWater is a project funded by the Irish Government and industry that is seeking to optimise water handling in processing plants. The results will potentially have impact not just in Ireland but globally wherever milk is processed. A forthcoming issue of the Journal will feature this research in a totally new Cluster format, comprising a scoping review accompanied by a number of related short communications. Irish research also features in the current issue, a collaboration with Italian groups resulting in a novel non-thermal method for reducing microbial load in mozzarella cheese (Lacivita et al. 2018). Italy is well represented in this issue (five papers) and I draw particular attention to the observation that fatty acid profiles of various milks differ before and after in vitro digestion designed to mimic conditions in the gut (Santillo et al. 2108); not a surprise perhaps, but nevertheless a salutary lesson for dietary intervention strategies. The Italian contribution to this issue is surpassed by papers from China (seven papers) including three papers that focus on different aspects of metabolic and cellular regulation. Insulin's role in regulating hepatocyte lipid metabolism via inhibition of AMP-activated protein kinase alpha is reported by $\mathrm{Yu} \mathrm{Li}$ and colleagues (Li et al. 2018). The liver is also the focus of a study of the role of sirtuins and specifically SIRT3 in postpartum oxidative stress regulation in dairy goats (Liu et al. 2018) whilst the mammary epithelial cell is the target of RagD interacting with the mTOR signalling pathway in regulation of casein synthesis and cell proliferation (Mu et al. 2018). Our Journal strives to balance production-related and utilisation-related papers, so I shall end by highlighting two studies that deal with product quality issues, firstly of feta cheese and the importance of para kappa-casein in the ripening process (Alexandraki \& Moatsou, 2018) and secondly of Greek yogurt and the use of a pectin/whey protein concentrate to reduce the generation of acid whey (Gyawali \& Ibrahim, 2018). Both of these papers involved members of our Editorial Board. The Board is looking for additional expertise in classical genetics, genomics and statistics. If you have such expertise and would like to join the Board, please contact the Editor. 


\section{References}

Alexandraki V \& Moatsou G (2018) Para-к-casein during the ripening and storage of low-pH, high-moisture feta cheese. Journal of Dairy Research 85 226-231

Gyawali R \& Ibrahim SA (2018) Addition of pectin and whey protein concentrate minimizes the generation of acid whey in Greek-style yogurt Journal of Dairy Research 85 238-242

Lacivita V, Conte A, Lyng JG, Arroyo C, Zambrini VA \& Del Nobile MA (2018) High intensity light pulses to reduce microbial load in fresh cheese. Journal of Dairy Research 85 232-237

Li X, Li Y, Ding H, Dong J, Zhang R, Huang D, Lei L, Wang Z, Liu G \& Li X (2018) Insulin suppresses the AMPK signaling pathway to regulate lipid metabolism in primary cultured hepatocytes of dairy cows. Journal of Dairy Research 85 157-162

Linzell JL \& Peaker M (1971) Mechanism of milk secretion. Physiological Reviews 51 564-597

Liu L, Yao L, Peng T, Wen L, Cai W, He J \& Jia X (2018) Hepatic Sirt3 expression declines postpartum in dairy goats. Journal of Dairy Research 85 163-166
Mekonnen MM \& Hoekstra AY (2016) Four billion people facing severe water scarcity. Science Advances 12 e1500323 doi: 10.1126/ sciadv.1500323

Mobasheri A \& Barrett-Jolley R (2014) Aquaporin water channels in the mammary gland: from physiology to pathophysiology and neoplasia. Journal of Mammary Gland Biology and Neoplasia 19 91-102

Mu Y, Zheng D, Wang C, Yu W \& Zhang X (2018) Ragd regulates amino acid mediated-casein synthesis and cell proliferation via mTOR signaling in cow mammary epithelial cells. Journal of Dairy Research 85 204-211

Oftedal OT (2002) The origin of lactation as a water source for parchmentshelled eggs. Journal of Mammary Gland Biology and Neoplasia 7 253-266

Olsson K (2005) Fluid balance in ruminants: adaptation to external and internal challenges. Annals of the New York Academy of Sciences 1040 156-161

Santillo A, Figliola L, Ciliberti MG, Caroprese M, Marino R \& Albenzio M (2018) Focusing on fatty acid profile in milk from different species after in vitro digestion. Journal of Dairy Research 85 257-262 